\title{
A Liver Transplant Patient on Everolimus Treatment Presented with Acute Anterior Myocardial Infarction: Does the Type of Drug-eluting Stent Matter?
}

\author{
Muhammet Gürdoğan, Kenan Yalta, Mustafa Adem Y1lmaztepe, Servet Altay, Ömer Ferudun Akkuş
}

Department of Cardiology, Trakya University School of Medicine, Edirne, Turkey

To the Editor,

Liver transplantation (LT) is the most effective management strategy for end-stage liver disease and hepatocellular carcinoma (1). Owing to the evolution of surgical techniques along with potent immunosuppressive agents and infection control, survival rates following LT have reached $90 \%$ and $80 \%$ at one and five years, respectively (1). In the general population, cardiovascular disease (CVD) constitutes the most common cause of adverse clinical outcomes in patients undergoing LT in the long-term (2). Primary percutaneous coronary intervention (PCI) is the recommended therapeutic strategy for ST-elevation myocardial infarction (STEMI) in post-LT patients (3). However, there exist no specific recommendations in the current literature regarding the most preferable type of drug-eluting stent (DES) during PCI in patients receiving long-term systemic immunosuppressive therapy.

A 55-year-old male patient was admitted to our clinic with chest pain. His electrocardiogram findings were consistent with an acute anterior STEMI. His history revealed chronic hepatitis $\mathrm{B}(+)$ and LT due to hepatocellular carcinoma three years earlier. Since his LT, the patient had been regularly receiving everolimus $0.75 \mathrm{mg}$ $(2 \times 1)$, tenofovir $245 \mathrm{mg}(1 \times 1)$, ursodeoxycholic acid $250 \mathrm{mg}$ $(2 \times 2)$, and esomeprazole $40 \mathrm{mg}(1 \times 1)$. The initial hemogram, prothrombin time - international normalized ratio and liver and kidney function tests were all within normal limits. There was no contraindication to dual antiplatelet therapy or statins. Coronary angiography revealed a $99 \%$ thrombosed subtotal bifurcation lesion in the left anterior descending coronary artery along with insignificant atherosclerotic plaques in other coronary arteries. The culprit lesion was successfully managed with the culotte technique using two everolimus-coated stents $(3.0 \times 38 \mathrm{~mm}$ and $3.0 \times 26 \mathrm{~mm})$.
Currently, there have been only a couple of published case reports describing DES implantation following acute coronary syndrome in post-LT patients. Therefore, there are no specific recommendations regarding the impact of the presence and type of systemic immunosuppressive treatment in these patients on the choice of DES type to be implanted in this setting (4). Echeverri et al. previously reported the successful implantation of zotarolimuscoated stents in two patients with familial hypercholesterolemia, which was caused by STEMI and unstable angina pectoris, respectively). These patients had already undergone systemic immunosuppressive therapy with tacrolimus in the post-LT setting (5). However, in this case, we agreed on the implantation of an everolimus-coated coronary stent in our STEMI patient for whom everolimus had also been used as a systemic immunosuppressive agent since his LT, potentially considering the fact of that the additive impact of systemic everolimus (on top of its local release by the DES in a paracrine manner) might significantly contribute to the prevention of long-term stent restenosis in this setting. In the future, more transplant patients with successful surgical procedure outcomes are anticipated; therefore, longer survival rates under immunosuppressive therapy will be encountered in daily cardiology practices. Therefore, there is an obvious necessity for further studies that will shed light on particular DES preferences in patients receiving systemic immunosuppressive therapy.

Conflict of Interest: No conflict of interest was declared by the authors.

\section{REFERENCES}

1. Russo FP, Ferrarese A, Zanetto A. Recent advances in understanding and managing liver transplantation. F1000Res 2016;5. pii: F1000 Faculty Rev-2895.

2. Khurmi NS, Chang YH, Eric Steidley D, Singer AL, Hewitt WR, Reddy KS, et al Hospitalizations for Cardiovascular Disease After Liver Transplantation in the United States. Liver Transpl 2018;24:1398-410.

\footnotetext{
Address for Correspondence: Muhammet Gürdoğan, Department of Cardiology, Trakya University School of Medicine, Edirne, Turkey Phone: +902842351041 e-mail: drmgurdogan@gmail.com ORCID: orcid.org/0000-0001-5650-9066 Received: 22 December 2019 Accepted: 27 December 2019 • DOI: 10.4274/balkanmedj.galenos.2019.2019.12.123 Available at www.balkanmedicaljournal.org 
3. Ibanez B, James S, Agewall S, Antunes MJ, Bucciarelli-Ducci C, Bueno H, et al. 2017 ESC Guidelines for the management of acute myocardial infarction in patients presenting with ST-segment elevation: The Task Force for the management of acute myocardial infarction in patients presenting with ST-segment elevation of the European Society of Cardiology (ESC). Eur Heart J 2018;39:119-77.

4. Işıkçelik F, Ağırbaş I, Kaya Tulunay C. An Analysis of Cost-Effectiveness of Stents Used in the Treatment of Coronary Artery Disease. Balkan Med J 2019;36:276-82.
5. Echeverri D, Jaime R. Cabrales JR, del Portillo JH, y Rey D. Drug-eluting stents in premature coronary disease in young people with homozygous familial hypercholesterolemia and prior liver transplantation Rev Colomb Cardiol 2017;24:351-60 